\title{
Developmental trends in children's typicality judgments
}

\author{
DAVID F. BJORKLUND and BARBARA E. THOMPSON \\ Florida Atlantic University, Boca Raton, Florida
}

and

\author{
PETER A. ORNSTEIN \\ University of North Carolina, Chapel Hill, North Carolina
}

\begin{abstract}
Category typicality norms from 12 natural language categories are presented for kindergarten, third-grade, sixth-grade, and college students. Subjects first selected examples of familiar word concepts and rated them on a 3-point scale in terms of category typicality. Age differences in the percentage of items included as category members were found primarily for the less typical items, with inclusion rates varying as a function of both age and typicality level. The absolute level of typicality judgments increased with age, although correlations between the children's and college students' ratings were generally significant for all three children's groups, with average correlations increasing somewhat with age. It was suggested that the rating data would be useful to developmental investigators interested in children's processing of category information.
\end{abstract}

Recent research in categorization (see Mervis \& Rosch, 1981) has suggested that natural language categories can be viewed as having indefinite boundaries and that membership in these categories is not determined unequivocally by sets of criterial features. Using a "prototype" model, Rosch and her colleagues (e.g., Rosch, 1973, 1975; Rosch \& Mervis, 1975) have argued that category instances vary in the degree to which they are representative of their categories (i.e., vary in typicality). Adult subjects demonstrate high intersubject agreement when they rate words in terms of category typicality (Rosch, 1973, 1975; Uyeda \& Mandler, 1980), and differences in rated typicality have been found to affect adults' performance in tasks involving category verification (e.g., Rips, Shoben, \& Smith, 1973; Rosch, 1973), same-different judgments (e.g., Rosch, 1975), and recall (e.g., Greenberg \& Bjorklund, 1981; Keller \& Kellas, 1978).

Developmentally, there is a suggestion that adultjudged typical category instances are integrated into children's natural language concepts before atypical

The authors would like to express their appreciation to the staff and students of Henderson University School, Boca Raton Elementary School, Boca Raton Middle School, J. C. Mitchell Elementary School, and the Training Depot for their cooperation in the execution of this study. We would also like to thank Genevieve Craft for her assistance in data collection, and an anonymous reviewer for helpful comments on the manuscript. Portions of this research were presented at the meeting of the Society for Research in Child Development, Boston, 1981. Requests for reprints should be sent to David F. Bjorklund, Department of Psychology, Florida Atlantic University, Boca Raton, Florida 33431. items are (e.g., Anglin, 1977; Nelson, 1974; Saltz, Soller, \& Sigel, 1972). However, to date, no studies have been reported in which children themselves have evaluated the typicality of category members. In the present study, children's category-selection decisions were supplemented with actual judgments of typicality. These data, in addition to extending the findings of other research concerning the nature of concept development, should be useful to investigators interested in children's processing of categorical information. For example, researchers have examined children's processing of adult-defined typical and atypical category instances in sentence-verification (Keller, 1982; Rosch, 1973) and category-priming (Duncan \& Kellas, 1978) tasks. It is possible that different patterns of results requiring different interpretations would have been obtained had these investigators used child-defined rather than adult-defined typicality judgments. Assessing children's processing of adult-defined typical and atypical category exemplars aids in discerning how children's concept utilization is progressing with respect to the adult standard. However, to the extent that children's category knowledge differs from that of adults, the use of child-generated typical and atypical category instances in developmental experiments will likely provide interpretations of children's concept utilization different from the interpretations arising from the use of adult norms. Furthermore, using childrather than adult-generated category norms may provide a more accurate reflection of age differences in the processing of categorical information rather than of age differences in knowledge base. 


\section{METHOD}

\section{Subjects}

Seventy-two children, 24 each ( 12 boys and 12 girls) from kindergarten, third grade, and six th grade, served as the subjects. In addition, 45 college students ( 10 males and 35 females) also participated. The mean ages were 5 years 8 months, 8 years 5 months, 11 years 5 months, and 25 years 9 months for the kindergarten, third-grade, sixth-grade, and college students, respectively. The children were selected from three public schools in Palm Beach County, Florida, and were from predominantly middle-class homes. The adults were undergraduate students enrolled in a human development course at Florida Atlantic University; their participation was voluntary.

\section{Task and Materials}

The subjects were asked to select from lists of words those that were examples of specified natural language categories, and then to rate each item on a 3-point scale in terms of how "typical" it was of its category. To simplify the rating task, the children's judgments of typicality were obtained by having them point to one of three black-and-white schematic faces located on a table in front of them. Each face was drawn on a $4 \times 6$ in. white index card, and each displayed a different expression: "smiling," "straight," and "frowning" faces represented "very good," "okay," and "poor" category exemplars, respectively. The adults used rating sheets that listed the items to be rated separately for each category.

The children were read lists of items from each of 12 natural language categories. The number of items per category ranged from 8 to 13. Eight of the categories (birds, clothing, fruit, furniture, tools, vegetables, vehicles, and weapons) had also been used by Rosch (1975), and only data from the 84 words in these categories are discussed in detail in this report (see Appendix A). Items in each of the four additional categories (body parts, buildings, dogs, musical instruments), along with their typicality ratings, are listed in Appendix B. Although not reported, the pattern of results for these four categories was similar to that for the eight categories analyzed here. The specific items used in this study were pilot tested with a sample of kindergarten children to ensure that even the youngest subjects tested would know the meanings of the words. For the eight categories studied by Rosch (1975), the items included ranged from highly typical to atypical, according to her adult sample; the experimenters' intuitions were used to select items with a comparable range of typicality for the four categories not examined by Rosch (1975). In addition, three to five noncategory items were included in each list as foils. Two random presentation orders were generated for the 12 categories, with the order of presentation of items within each category being determined by two additional orders.

In addition to the above, each child was presented the two practice categories toys and food, both of which were represented by four category members (varying in typicality) and two noncategory members. These practice categories were introduced to ensure that the subjects understood the task demands

\section{Procedure}

Each kindergarten, third-, and sixth-grade child was tested individually and told to pretend that there was a person from outer space who had just landed on earth. The children were told that the spaceman knew nothing about earth, and that they could help him understand our world by answering some questions for the experimenter. First, the experimenter read a list of practice items and asked the child to determine whether each item was a member of the concept designated by the experimenter (e.g., "Is a ball a toy?"). Following the selection of all category-appropriate items, the children were reread all of the words that they had designated to be category members and were asked to rate the practice items from each category on a 3-point scale, with assistance from the experimenter. They were told that if an item was a "very good" example of its category, they were to point to the "smiling" schematic face located in front of them. "Very good" items were ones that might come to mind immediately when thinking of the category, and ones that would be very helpful to the spaceman in understanding the category (such as "hamburger" for the concept "food"). "Okay" examples corresponded to the "straight" face and were items (such as "beans") that would help the spaceman somewhat to understand the category, but not as well as would the "very good" items. "Poor" examples corresponded to the "frowning" face and were items that were category members, but ones that would not help the spaceman understand the category very well (such as "popsicle"). Following the two practice categories, the entire procedure was repeated with the 12 test categories. Each item received a score ranging from 0 (not selected as a category member) to 3 (a "very good," or typical, category exemplar). Scores of 1 and 2 corresponded to "poor" and "okay" category members, respectively.

The experimenter stressed to the child that he/she was to determine how good an example each item was of its category and not to tell the experimenter how much he/she liked the items. "Popsicle" was used as an example of an item that the children probably liked very much, but one which was not a typical example of food. Our concern that young children may have evaluated items in terms of "likes" and "dislikes" was dissipated by an analysis of data collected from age-mates of the subjects tested here $(\mathrm{N}=32$ per grade), in which subjects were asked to rate items on a 3-point scale in terms of "likes" and "dislikes." Correlations between these subjects" "likes" and the typicality judgments reported herein were of a moderate magnitude (median correlations $=.46, .35, .34$, and .29 for kindergarten through adult subjects, respectively), and did not vary with grade level. There is no reason to believe, therefore, that young children were using an affective dimension in rating items, with the older children and adults evaluating items in terms of category typicality.

The adults were tested as a group and participated in a procedure similar to that used by Rosch (1975). Using a rating scale identical to that used with the children, the adults recorded their responses on sheets of paper.

\section{RESULTS AND DISCUSSION}

\section{Percentage of Items Included per Category}

The percentage of subjects that included each item as an appropriate category member is presented by grade and category for each item in Appendix A. Age differences in the percentage of items included as category instances were assessed in a one-way analysis of variance, collapsed across the eight categories, with items as the random variable (i.e., the percentage score of each item at each grade was entered into the analysis of variance). The analysis was significant $[F(3,249)=46.43, p<.001]$, with subsequent Newman-Keuls tests $(p<.05)$ indicating that the percentage of items included as appropriate category exemplars increased significantly at each successive grade level (percentage included $=79.0 \%, 85.6 \%$, $90.3 \%$, and $97.1 \%$ for kindergarten through college students, respectively).

Further inspection of the data suggested that differences in the percentage of items included as appropriate category exemplars were primarily due to children failing to select the less typical adult-defined items as category members. To test this, the 84 items were divided into equal quartiles based on the college students' 


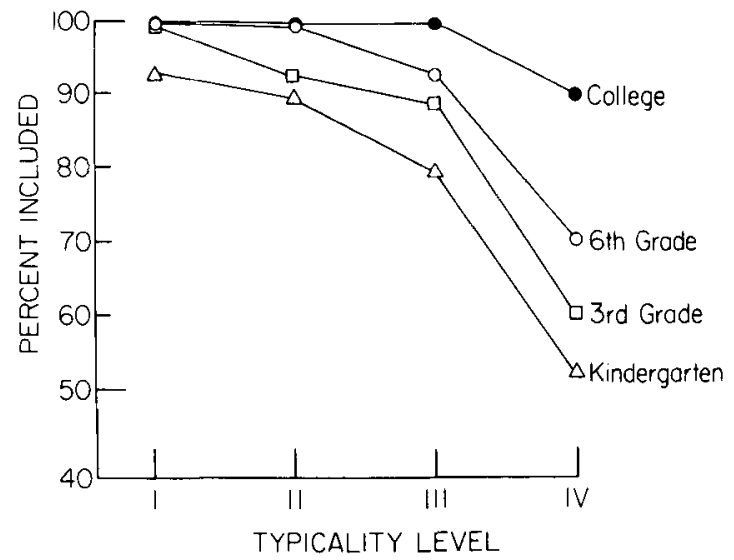

Figure 1. Percentage included, by grade and typicality level.

typicality ratings, and age differences in the percentage of items included as a function of the level of adultdefined typicality were evaluated (see Figure 1). Level I represented the $21(25 \%)$ highest rated items in the college students' data, and Level IV represented the 21 (25\%) lowest rated items in their data. A grade $x$ typicality level analysis of variance, with items serving as the random variable, produced a significant two-way interaction $[F(9,240)=9.47, p<.01]$. This significant effect reflects the fact that differences in inclusion rates between the children and adults increased as adult-defined typicality scores decreased. ${ }^{1}$ This finding confirms the observations of others (e.g., Anglin, 1977; Nelson, 1974; Saltz et al., 1972) and supports the position that category boundaries generally broaden with age. Note that the magnitude of this effect varied somewhat between categories, indicating that children may acquire some categories earlier than others.

\section{Typicality Ratings}

Typicality scores were averaged over subjects, separately by grade level, to produce an average typicality rating for each item in every category (see Appendix A).

higher the rating (with 3 as a maximum and 0 as a minimum), the greater the judged typicality. Adjusted typicality scores were also computed by averaging only the ratings of items that were included as category instances (i.e., all 0 ratings were eliminated, and the $n$ was adjusted correspondingly). Mean typicality scores increased significantly at each successive grade level (Newman-Keuls, $\mathrm{p}<.05$ ) for both the adjusted (means = $2.24,2.37,2.56$, and 2.73 for kindergarten through college subjects, respectively) and unadjusted (means = $1.79,2.07,2.32$, and 2.66 for kindergarten through college subjects, respectively) typicality scores $[\mathrm{Fs}(3,249)$ $\geqslant 86.15, \mathrm{p}<.001]$.

In order for these age changes in typicality judgments to be evaluated further, the unadjusted ratings for each category of the three children's groups were correlated with the ratings of the college students. These correlations are presented in Table 1 . As can be seen, the correlations were generally high and significant at all ages. However, average correlations did tend to increase with age, with correlations between the children's and college students' ratings increasing at each successive grade level (sixth grade $>$ third grade $>$ kindergarten) for six of the eight categories. The likelihood that the magnitude of the correlations at the three grade levels would be so ordered for six of eight categories is significantly less than what would be expected by chance $(p<.001){ }^{2}$ This finding suggests that although there is a significant correspondence between the ratings of the children and the adults, differences in judged typicality (and thus in conceptual prototypes) vary somewhat with age.

The typicality ratings of the college students were also correlated (Spearman rank-order) with those obtained by Rosch (1975) and by Uyeda and Mandler (1980) and are presented in Table 2. As can be seen

Table 1

Pearson Product-Moment Correlations Between Children's and College Students' Typicality Ratings by Grade and Category

\begin{tabular}{lclll}
\hline Category & N & $\begin{array}{l}\text { Kinder- } \\
\text { garten }\end{array}$ & $\begin{array}{l}\text { Third } \\
\text { Grade }\end{array}$ & $\begin{array}{c}\text { Sixth } \\
\text { Grade }\end{array}$ \\
\hline Birds & 11 & .50 & $.84^{*}$ & $.92^{*}$ \\
Clothing & 11 & $.72^{*}$ & $.84^{*}$ & $.88^{*}$ \\
Fruit & 11 & $.75^{*}$ & $.88^{*}$ & $.80^{*}$ \\
Furniture & 11 & $.90^{*}$ & $.95^{*}$ & $.96^{*}$ \\
Tools & 13 & $.67^{* *}$ & $.85^{*}$ & $.90^{*}$ \\
Vegetables & 10 & $.72^{* *}$ & .15 & $.83^{*}$ \\
Vehicles & 9 & $.79^{*}$ & $.91^{*}$ & $.93^{*}$ \\
Weapons & 8 & $.68 \dagger$ & $.84^{*}$ & $.96^{*}$ \\
Mean & & .72 & .78 & .90 \\
Median & & .72 & .84 & .92 \\
\hline
\end{tabular}

$* p<.01 . \quad * * p<.05 . \quad t_{p}<.10$.

Table 2

Spearman Rank-Order Correlations Between Typicality Ratings of College Students With Ratings From Rosch (1975) and Uyeda and Mandler (1980)

\begin{tabular}{lll}
\hline \multicolumn{1}{c}{ Category } & Rosch & $\begin{array}{c}\text { Uyeda \& } \\
\text { Mandler }\end{array}$ \\
\hline Furniture & $.96^{*}$ & $.81^{*}$ \\
Clothing & $.89^{*}$ & $.80^{*}$ \\
Birds & $.85^{*}$ & $.76^{* *}$ \\
Tools & $.50^{* *}$ & .22 \\
Fruit & $.96^{*}$ & $.90^{*}$ \\
Vehicles & $.95^{*}$ & $.83^{*}$ \\
Vegetables & $.92^{*}$ & $.83^{*}$ \\
Weapons & $.95^{*}$ & $.94^{*}$ \\
Body Parts & & $.84^{*}$ \\
Musical Instruments & & $.81^{*}$ \\
Mean & .87 & .77 \\
Median & .94 & .82 \\
\hline
\end{tabular}

${ }^{*} p<.01 . \quad * * p<.10$. 
from Table 2 , these analyses indicate considerable agreement between the college-student ratings in this study and the ratings in the Rosch (1975) and Uyeda and Mandler (1980) studies, despite differences in the rating scales (i.e., a 3-point scale used here vs. a 7-point scale used by Rosch and by Uyeda and Mandler).

The rating data presented here should be useful to investigators concerned with children's processing of category information. For example, using child-defined rather than adult-defined category exemplars would increase the likelihood that children would be familiar with the categorical nature of the stimulus materials. A number of researchers have recently stressed the importance that a child's knowledge base may play in the execution of a cognitive task. More precisely, what a child knows affects how the information in a cognitive task is processed (see Chi, 1978, and Ornstein \& Naus, in press). With respect to category typicality, the use of adult-defined norms may not reveal how children process typical versus atypical category exemplars, per se, because many of the adult-defined typical and atypical items may not be similarly perceived by the children. In such cases, age differences in information processing are confounded with age differences in knowledge base. Such confounds can be avoided (or at least minimized) by the use of child-generated norms.

\section{REFERENCES}

ANGlin, J. M. Word, object, and conceptual development. New York: Norton, 1977.

CHI, M. T. H. Knowledge structure and memory development. In R. Siegler (Ed.), Children's thinking: What develops? Hillsdale, N.J: Erlbaum, 1978.

Duncan, E. M., \& Kellas, G. Developmental changes in the internal structure of semantic categories. Journal of Experimental Child Psychology, 1978, 26, 328-340.

Greenberg, M. S., \& BJorkuund, D. F. Category typicality in free recall: Effects of feature overlap or differential category encoding? Journal of Experimental Psychology: Human Learning \& Memory, 1981, 7, 145-147.

KELLER, D. Developmental effects of typicality and superordinate property dominance in sentence verification. Journal of Experimental Child Psychology, 1982, 33, 288-297.
Keller, D., \& Kellas, G. Typicality as a dimension of encoding. Journal of Experimental Psychology: Human Learning \& Memory, 1978, 4, 78-85.

Mervis, C. B., \& Rosch, E. Categorization of natural objects. Annual Review of Psychology, 1981, 32, 89-115.

NeLson, $K$. Variations in children's concepts by age and category. Child Development, 1974, 45, 577-584.

Ornstein, P. A., \& Naus, M. Effects of the knowledge base on children's memory processes. In J. B. Sidowski (Ed.), Conditioning, cognition, and methodology: Contemporary issues in experimental psychology. Hillsdale, N.J: Erlbaum, in press.

Rips, L. J., Shopen, E. J., \& Smith, E. E. Semantic distance and the verification of semantic relations. Journal of Verbal Learning and Verbal Behavior, 1973, 12, 1-20.

Rosch, E. On the internal structure of perceptual and semantic categories. In T. E. Moore (Ed.), Cognitive development and the acquisition of language. New York: Academic Press, 1973.

Rosch, E. Cognitive representations of semantic categories. Journal of Experimental Psychology: General, 1975, 7, 192-233.

Rosch, E., \& ME Rvis, C. B. Family resemblances: Studies on the internal structure of categories. Cognitive Psychology, 1975, 7, 573-605.

Saltz, E., Soller, E., \& Siegel, I. E. The development of natural language concepts. Child Development, 1972, 43, 1191-1202.

Uyeda, K. M., \& Mandler, G. Prototypicality norms for 28 semantic categories. Behavior Research Methods \& Instrumentation, 1980, 12, 587-595.

\section{NOTES}

1. Quartiles were also determined based on adjusted typicality scores of adults, where all " 0 " scores (i.e., items not selected as category members) were eliminated and the $n$ was adjusted appropriately. The pattern of data that resulted when these adjusted scores were used to determine quartiles was virtually identical to the pattern that resulted when the unadjusted typicality scores were used.

2. Unadjusted typicality scores, rather than adjusted scores, were used because it was believed that to omit ratings of " 0 " from the computations would result in overestimation of judged typicality for some items (thus altering the rank order of items) when exclusion rates were high (e.g., for the kindergarten children). However, these correlations were computed and yielded results similar to those found with the unadjusted ratings. Correlations increased with grade level (median correlations between the children's and college students' adjusted ratings $=.43, .75$, and .81 for kindergarten, third-grade, and sixthgrade children, respectively). These correlations increased at each successive grade level (sixth grade $>$ third grade $>$ kindergarten) for five of the eight categories $(p<.005)$.

Appendix A

Mean Typicality Ratings a and Percentage Included by Grade Level for Categories Used in This Experiment

\begin{tabular}{|c|c|c|c|c|c|c|c|c|}
\hline \multirow[t]{2}{*}{ Exemplar } & \multicolumn{4}{|c|}{ Typicality Rating } & \multicolumn{4}{|c|}{ Percentage Included } \\
\hline & College & Sixth & Third & $\begin{array}{l}\text { Kinder- } \\
\text { garten }\end{array}$ & College & Sixth & Third & $\begin{array}{r}\text { Kinder- } \\
\text { garten }\end{array}$ \\
\hline \multicolumn{9}{|c|}{ Birds $c$} \\
\hline Eagle & 2.96 & 2.83 & 2.46 & $1.96(2.35)$ & 100 & 100 & 100 & 83 \\
\hline Bluejay & 2.93 & 2.88 & 2.67 & 2.42 & 100 & 100 & 100 & 100 \\
\hline Parrot & 2.91 & 2.88 & $2.58(2.70)$ & $2.21(2.30)$ & 100 & 100 & 96 & 96 \\
\hline Sparrow & $2.89(2.96)$ & 2.79 & $1.92(2.42)$ & $1.17(2.15)$ & 98 & 100 & 79 & 54 \\
\hline Cardinal & 2.87 & $2.67(2.78)$ & $2.38(2.48)$ & $1.50(2.12)$ & 100 & 96 & 96 & 71 \\
\hline Owl & 2.78 & $2.46(2.57)$ & $2.21(2.41)$ & $1.58(2.11)$ & 100 & 96 & 92 & 75 \\
\hline Peacock & $2.69(2.75)$ & 2.21 & 2.42 & $1.38(2.06)$ & 98 & 100 & 100 & 67 \\
\hline Pelican & $2.64(2.70)$ & 2.42 & $2.00(2.18)$ & $1.54(2.18)$ & 98 & 100 & 92 & 71 \\
\hline
\end{tabular}


Appendix A (continued)

\begin{tabular}{|c|c|c|c|c|c|c|c|c|}
\hline \multirow[t]{2}{*}{ Exemplar } & \multicolumn{4}{|c|}{ Typicality Rating } & \multicolumn{4}{|c|}{ Percentage Included } \\
\hline & College & Sixth & Third & $\begin{array}{l}\text { Kinder- } \\
\text { garten }\end{array}$ & College & Sixth & Third & $\begin{array}{r}\text { Kinder- } \\
\text { garten }\end{array}$ \\
\hline Stork & $2.47(2.58)$ & $2.08(2.17)$ & $1.79(2.05)$ & $0.92(1.83)$ & 96 & 96 & 88 & 50 \\
\hline Duck & $2.40(2.57)$ & $1.88(2.05)$ & $1.79(2.39)$ & $1.25(2.14)$ & 93 & 92 & 75 & 58 \\
\hline Penguin & $1.91(2.46)$ & $1.79(2.15)$ & $1.50(2.00)$ & $1.42(2.00)$ & 78 & 83 & 75 & 71 \\
\hline Mean & $2.68(2.77)$ & $2.44(2.52)$ & $2.16(2.38)$ & $1.58(2.15)$ & 96.45 & 96.64 & 90.27 & 72.36 \\
\hline \multicolumn{9}{|c|}{ Clothingd } \\
\hline Coat & 2.98 & 2.75 & $2.38(2.48)$ & $2.04(2.45)$ & 100 & 100 & 96 & 83 \\
\hline Dress & 2.98 & 3.00 & 2.50 & $2.46(2.57)$ & 100 & 100 & 100 & 96 \\
\hline Pants & 2.98 & 2.96 & 2.79 & $2.58(2.70)$ & 100 & 100 & 100 & 96 \\
\hline Shirt & 2.98 & 2.96 & 2.92 & 2.50 & 100 & 100 & 100 & 100 \\
\hline Socks & 2.87 & 2.38 & 2.08 & $2.00(2.18)$ & 100 & 100 & 100 & 92 \\
\hline Shoes & $2.60(2.66)$ & $1.79(2.53)$ & $1.50(2.40)$ & $1.21(2.23)$ & 98 & 71 & 63 & 54 \\
\hline Tie & 2.53 & 2.38 & $2.00(2.18)$ & $1.88(2.25)$ & 100 & 100 & 92 & 83 \\
\hline Gloves & 2.51 & 2.25 & $2.00(2.18)$ & $1.50(2.25)$ & 100 & 100 & 92 & 67 \\
\hline Hat & 2.44 & $1.67(2.22)$ & $1.71(1.95)$ & $1.71(2.41)$ & 100 & 75 & 88 & 71 \\
\hline Scarf & 2.40 & 2.13 & $1.92(2.09)$ & $2.13(2.32)$ & 100 & 100 & 92 & 92 \\
\hline Belt & 2.33 & $1.58(1.90)$ & $1.58(2.00)$ & $1.42(2.13)$ & 100 & 83 & 79 & 67 \\
\hline Mean & $2.69(2.70)$ & $2.35(2.50)$ & $2.13(2.32)$ & $1.95(2.36)$ & 99.82 & 93.55 & 91.09 & 81.91 \\
\hline \multicolumn{9}{|c|}{ Fruite } \\
\hline Peach & 2.98 & 2.96 & 2.71 & $2.08(2.27)$ & 100 & 100 & 100 & 92 \\
\hline Pear & 2.98 & 2.83 & $2.50(2.61)$ & $2.38(2.48)$ & 100 & 100 & 96 & 96 \\
\hline Banana & 2.93 & 2.88 & 2.15 & $2.42(2.52)$ & 100 & 100 & 100 & 96 \\
\hline Grapes & 2.91 & $2.75(2.87)$ & $2.33(2.55)$ & $2.08(2.38)$ & 100 & 96 & 92 & 88 \\
\hline Strawberries & 2.84 & 2.79 & $2.38(2.59)$ & $2.33(2.44)$ & 100 & 100 & 92 & 96 \\
\hline Cherries & $2.78(2.84)$ & $2.58(2.82)$ & $2.25(2.70)$ & $1.83(2.32)$ & 98 & 92 & 83 & 79 \\
\hline Raspberries & $2.78(2.84)$ & $2.67(2.78)$ & $2.04(2.23)$ & $1.67(2.22)$ & 98 & 96 & 92 & 75 \\
\hline Watermelon & $2.71(2.84)$ & $2.46(2.57)$ & $2.13(2.43)$ & $2.50(2.61)$ & 96 & 96 & 88 & 96 \\
\hline Lemon & $2.67(2.73)$ & $1.83(2.10)$ & $1.75(2.10)$ & $1.58(2.11)$ & 98 & 88 & 83 & 75 \\
\hline Lime & $2.64(2.70)$ & $1.75(2.10)$ & $1.50(2.00)$ & $1.33(2.00)$ & 98 & 83 & 75 & 67 \\
\hline Tomato & $1.42(2.37)$ & $1.42(2.43)$ & $0.88(2.10)$ & $0.96(2.30)$ & 60 & 58 & 42 & 42 \\
\hline Mean & $2.69(2.81)$ & $2.45(2.65)$ & $2.06(2.38)$ & $1.92(2.33)$ & 95.27 & 91.73 & 85.73 & 82.00 \\
\hline \multicolumn{9}{|c|}{ Furniture $^{f}$} \\
\hline Chair & 2.98 & 2.88 & 2.50 & 2.42 & 100 & 100 & 100 & 100 \\
\hline Couch & 2.98 & 2.96 & 2.79 & 2.33 & 100 & 100 & 100 & 100 \\
\hline Dresser & 2.98 & $2.54(2.65)$ & $2.42(2.64)$ & $1.96(2.47)$ & 100 & 96 & 92 & 79 \\
\hline Table & 2.93 & 2.67 & 2.54 & $2.17(2.26)$ & 100 & 100 & 100 & 96 \\
\hline Bed & 2.89 & 2.83 & 2.67 & $2.08(2.63)$ & 100 & 100 & 100 & 79 \\
\hline Desk & 2.89 & $2.38(2.71)$ & $2.21(2.52)$ & $1.96(2.35)$ & 100 & 88 & 88 & 83 \\
\hline Bookcase & $2.62(2.68)$ & $1.67(2.22)$ & $1.46(2.33)$ & $1.00(2.40)$ & 98 & 75 & 63 & 42 \\
\hline Lamp & $2.24(2.29)$ & $1.46(2.06)$ & $1.79(2.39)$ & $1.63(2.44)$ & 98 & 71 & 75 & 67 \\
\hline Television & $1.89(2.07)$ & $1.29(2.21)$ & $1.50(2.25)$ & $1.42(2.43)$ & 91 & 58 & 67 & 58 \\
\hline Clock & $1.27(1.73)$ & $0.75(2.57)$ & $0.83(2.00)$ & $0.63(2.50)$ & 73 & 29 & 42 & 25 \\
\hline Fan & 0.89 (1.48) & $0.25(2.00)$ & $0.17(1.33)$ & $0.46(2.20)$ & 60 & 13 & 13 & 21 \\
\hline Mean & $2.41(2.54)$ & $1.97(2.52)$ & $1.90(2.36)$ & $1.64(2.40)$ & 92.73 & 75.45 & 76.36 & 68.18 \\
\hline \multicolumn{9}{|c|}{ Toolsg } \\
\hline Hammer & 3.00 & 2.88 & 2.88 & 2.21 & 100 & 100 & 100 & 100 \\
\hline Screwdriver & 3.00 & 2.88 & 2.67 & 2.33 & 100 & 100 & 100 & 100 \\
\hline Wrench & 3.00 & 2.83 & 2.63 & $2.17(2.36)$ & 100 & 100 & 100 & 92 \\
\hline Saw & 2.98 & 2.83 & 2.75 & 2.00 & 100 & 100 & 100 & 100 \\
\hline Electric Drill & 2.91 & 2.79 & 2.63 & $1.79(1.96)$ & 100 & 100 & 100 & 92 \\
\hline Pliers & 2.91 & 2.75 & 2.50 & $2.13(2.32)$ & 100 & 100 & 100 & 92 \\
\hline Axe & 2.67 & $2.17(2.36)$ & $2.08(2.17)$ & $1.38(2.06)$ & 100 & 92 & 96 & 67 \\
\hline File & $2.42(2.66)$ & $1.75(2.33)$ & $0.58(2.00)$ & $1.17(2.33)$ & 91 & 75 & 29 & 50 \\
\hline Knife & 2.36 & $1.46(2.06)$ & $0.67(2.67)$ & $0.08(1.00)$ & 100 & 71 & 25 & 8 \\
\hline Scissors & 2.33 & $1.75(2.10)$ & $0.67(1.78)$ & $0.54(2.17)$ & 100 & 83 & 38 & 25 \\
\hline Nails & $2.09(2.35)$ & $2.17(2.48)$ & $1.79(2.15)$ & $1.79(1.96)$ & 89 & 88 & 83 & 92 \\
\hline Pencil & $1.78(2.00)$ & $1.13(2.08)$ & $0.25(2.00)$ & $0.17(2.00)$ & 89 & 54 & 13 & 8 \\
\hline Ladder & $1.67(2.03)$ & $1.54(2.31)$ & $0.88(2.10)$ & $1.46(2.69)$ & 82 & 67 & 42 & 54 \\
\hline Mean & $2.55(2.63)$ & $2.23(2.51)$ & $1.77(2.38)$ & $1.48(2.11)$ & 96.23 & 86.92 & 71.23 & 67.69 \\
\hline \multicolumn{9}{|c|}{ Vegetables $^{h}$} \\
\hline Peas & & $2.29(2.50)$ & $1.58(1.90)$ & 2.29 & 100 & 92 & 83 & 100 \\
\hline Carrot & 2.93 & 3.00 & $2.63(2.74)$ & 2.58 & 100 & 100 & 96 & 100 \\
\hline Lettuce & 2.93 & 2.75 & $2.13(2.43)$ & 2.46 & 100 & 100 & 88 & 100 \\
\hline
\end{tabular}


Appendix A (continued)

\begin{tabular}{|c|c|c|c|c|c|c|c|c|}
\hline \multirow[t]{2}{*}{ Exemplar } & \multicolumn{4}{|c|}{ Typicality Rating } & \multicolumn{4}{|c|}{ Percentage Included } \\
\hline & College & Sixth & Third & $\begin{array}{l}\text { Kinder- } \\
\text { garten }\end{array}$ & College & Sixth & Third & $\begin{array}{c}\text { Kinder- } \\
\text { garten }\end{array}$ \\
\hline Corn & $2.91(2.98)$ & $2.58(2.70)$ & $2.13(2.55)$ & 2.42 & 98 & 96 & 83 & 100 \\
\hline Celery & 2.87 & 2.83 & $2.13(2.55)$ & $1.96(2.24)$ & 100 & 100 & 83 & 88 \\
\hline Squash & 2.84 & $2.46(2.68)$ & $1.50(2.12)$ & $1.42(1.79)$ & 100 & 92 & 71 & 79 \\
\hline Cucumber & $2.80(2.86)$ & 2.71 & $2.13(2.32)$ & $2.17(2.36)$ & 98 & 100 & 92 & 92 \\
\hline Onion & $2.69(2.75)$ & $1.92(2.09)$ & $1.71(1.95)$ & $1.83(2.00)$ & 98 & 92 & 88 & 92 \\
\hline Potatoes & $2.56(2.88)$ & $2.17(2.36)$ & $2.71(2.83)$ & $1.92(2.42)$ & 89 & 92 & 96 & 79 \\
\hline Mushroom & $2.44(2.68)$ & $1.33(2.29)$ & $1.42(2.00)$ & $1.29(1.94)$ & 91 & 58 & 71 & 67 \\
\hline Mean & $2.79(2.87)$ & $2.40(2.59)$ & $2.01(2.34)$ & $2.03(2.25)$ & 97.40 & 92.20 & 85.10 & 89.70 \\
\hline \multicolumn{9}{|c|}{ Vehiclesi } \\
\hline Bus & 2.98 & 2.54 & 2.63 & 2.50 & 100 & 100 & 100 & 100 \\
\hline Car & 2.98 & 2.88 & 2.75 & 2.46 & 100 & 100 & 100 & 100 \\
\hline Truck & 2.98 & 2.83 & 2.63 & 2.17 & 100 & 100 & 100 & 100 \\
\hline Jeep & 2.96 & 2.79 & 2.63 & $2.42(2.52)$ & 100 & 100 & 100 & 96 \\
\hline Train & 2.89 & 2.71 & $2.50(2.61)$ & 2.63 & 100 & 100 & 96 & 100 \\
\hline Helicopter ${ }^{j}$ & 2.71 & $2.33(2.67)$ & $2.17(2.36)$ & 2.42 & 100 & 88 & 92 & 100 \\
\hline Airplane & $2.67(2.79)$ & $2.54(2.91)$ & $2.63(2.86)$ & 2.50 & 96 & 88 & 92 & 100 \\
\hline Bicycle & 2.58 & $2.29(2.50)$ & $2.04(2.23)$ & $1.96(2.24)$ & 100 & 92 & 92 & 88 \\
\hline Tricycle & $2.31(2.36)$ & $1.63(1.95)$ & $1.63(1.77)$ & $1.33(1.78)$ & 98 & 83 & 92 & 75 \\
\hline Mean & $2.78(2.80)$ & $2.50(2.64)$ & $2.40(2.50)$ & $2.27(2.36)$ & 99.33 & 94.56 & 96.00 & 95.44 \\
\hline \multicolumn{9}{|c|}{ Weaponsk } \\
\hline Gun & 2.98 & 2.92 & 2.67 & $1.50(1.80)$ & 100 & 100 & 100 & 83 \\
\hline Rifle & 2.96 & 2.88 & $2.50(2.73)$ & $1.50(2.00)$ & 100 & 100 & 92 & 75 \\
\hline Sword & 2.93 & 2.75 & $2.38(2.48)$ & 1.92 & 100 & 100 & 96 & 100 \\
\hline Knife & 2.91 & $2.38(2.59)$ & $1.92(2.00)$ & $1.38(1.83)$ & 100 & 92 & 96 & 75 \\
\hline Cannon & 2.84 & 2.63 & $2.08(2.38)$ & $1.13(1.80)$ & 100 & 100 & 88 & 63 \\
\hline Spear & 2.78 & 2.63 & 2.50 & $2.00(2.09)$ & 100 & 100 & 100 & 96 \\
\hline Axe & 2.44 & $1.92(2.30)$ & $1.42(2.00)$ & $1.25(2.00)$ & 100 & 83 & 71 & 63 \\
\hline Rock & $1.73(1.81)$ & $1.29(2.07)$ & $1.25(1.77)$ & $0.79(1.90)$ & 96 & 63 & 71 & 42 \\
\hline Mean & $2.70(2.71)$ & $2.43(2.60)$ & $2.09(2.32)$ & $1.43(1.92)$ & 99.50 & 92.25 & 89.25 & 74.63 \\
\hline
\end{tabular}

a Typicality ratings ranged from 3 (highly typical) to 1 (atypical). A score of 0 was given to items not included as category exemplars. Adjusted typicality scores, when different from unadjusted scores, are presented in parentheses. bPercentage of subjects at each grade level who included an item as an appropriate category exemplar. Percentage included and typicality ratings were based on a sample of 24 subjects in each of the kindergarten, third, and sixth grades, and 45 subjects in the college student sample. cFoil items used for this category: airplane, bees, squirrel, teepee, tiger. $\mathrm{d}$ Foil items used for this category: arm, comb, horseshoe, pipe, stagecoach. $\quad$ Foil items used for this category: flowers, hotdog, puzzle, steak, tree. $\mathrm{f}_{F}$ Foil items used for this category: candle,

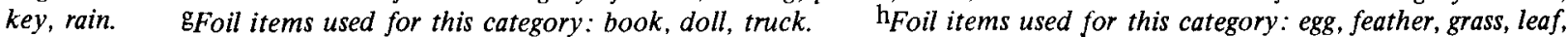
tree. $\quad \mathrm{i} F o i l$ items used for this category: cow, saddle, snowman, traffic light, wheel. $\mathrm{j}$ Helicopter was not included in the Rosch

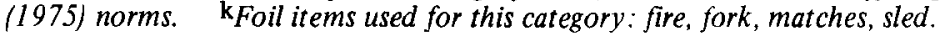

Appendix B

Mean Typicality Ratings ${ }^{a}$ and Percentage Included ${ }^{b}$ by Grade Level for Categories Not Reported in This Study

\begin{tabular}{|c|c|c|c|c|c|c|c|c|}
\hline \multirow[t]{2}{*}{ Exemplar } & \multicolumn{4}{|c|}{ Typicality Rating } & \multicolumn{4}{|c|}{ Percentage Included } \\
\hline & College & Sixth & Third & $\begin{array}{l}\text { Kinder- } \\
\text { garten }\end{array}$ & College & Sixth & Third & $\begin{array}{r}\text { Kinder- } \\
\text { garten }\end{array}$ \\
\hline \multicolumn{9}{|c|}{ Body Partsc } \\
\hline Arm & 3.00 & 2.92 & 2.71 & 2.29 & 100 & 100 & 100 & 100 \\
\hline Foot & 2.98 & 2.83 & 2.46 & $2.04(2.13)$ & 100 & 100 & 100 & 96 \\
\hline Hand & 2.98 & 2.92 & 2.83 & $2.46(2.57)$ & 100 & 100 & 100 & 96 \\
\hline Leg & 2.98 & 2.88 & 2.83 & 2.38 & 100 & 100 & 100 & 100 \\
\hline Fingers & 2.93 & 2.92 & 2.29 & 2.54 & 100 & 100 & 100 & 100 \\
\hline Ear & 2.89 & 2.67 & 2.42 & $2.00(2.18)$ & 100 & 100 & 100 & 92 \\
\hline Elbow & $2.87(2.94)$ & 2.71 & 2.33 & 2.42 & 100 & 100 & 100 & 100 \\
\hline Neck & 2.87 & 2.71 & 2.50 & $2.17(2.36)$ & 98 & 100 & 100 & 92 \\
\hline Wrist & 2.80 & 2.54 & 2.33 & $1.88(2.25)$ & 100 & 100 & 100 & 83 \\
\hline Hair & $2.13(2.23)$ & $2.04(2.13)$ & $2.13(2.22)$ & $1.79(2.26)$ & 96 & 96 & 96 & 79 \\
\hline Mean & $2.84(2.86)$ & $2.71(2.72)$ & $2.48(2.49)$ & $2.20(2.34)$ & 99.40 & 99.60 & 99.60 & 93.80 \\
\hline
\end{tabular}


Appendix B (continued)

\begin{tabular}{|c|c|c|c|c|c|c|c|c|}
\hline \multirow[t]{2}{*}{ Exemplar } & \multicolumn{4}{|c|}{ Typicality Rating } & \multicolumn{4}{|c|}{ Percentage Included } \\
\hline & College & Sixth & Third & $\begin{array}{c}\text { Kinder- } \\
\text { garten }\end{array}$ & College & Sixth & Third & $\begin{array}{r}\text { Kinder- } \\
\text { garten }\end{array}$ \\
\hline \multicolumn{9}{|c|}{ Buildings d } \\
\hline Church & 2.89 & 2.63 & $2.50(2.61)$ & $1.96(2.61)$ & 100 & 100 & 96 & 75 \\
\hline School & 2.86 & 2.71 & 2.58 & $1.75(2.33)$ & 100 & 100 & 100 & 75 \\
\hline Barn & 2.84 & $1.96(2.14)$ & $1.71(2.16)$ & $0.96(2.56)$ & 100 & 92 & 79 & 38 \\
\hline House & 2.84 & $2.58(2.82)$ & $2.38(2.59)$ & $0.96(2.09)$ & 100 & 92 & 92 & 46 \\
\hline Bank & $2.75(2.81)$ & 2.79 & 2.67 & $1.33(2.29)$ & 98 & 100 & 100 & 58 \\
\hline Castle & 2.73 & 2.71 & 2.50 & $2.00(2.29)$ & 100 & 100 & 100 & 88 \\
\hline Igloo & 2.21 & $1.33(1.60)$ & $0.96(1.64)$ & $0.63(2.14)$ & 100 & 83 & 58 & 29 \\
\hline Mean & $2.73(2.74)$ & $2.39(2.49)$ & $2.19(2.39)$ & $1.37(2.33)$ & 99.71 & 95.29 & 89.29 & 58.43 \\
\hline \multicolumn{9}{|c|}{ Dogs $\mathrm{e}$} \\
\hline German Shepard & 3.00 & 2.67 & 2.67 & 2.54 & 100 & 100 & 100 & 100 \\
\hline Collie & 2.98 & 2.96 & $2.17(2.60)$ & $1.67(2.35)$ & 100 & 100 & 83 & 71 \\
\hline Cocker Spaniel & 2.96 & 2.71 & $2.25(2.57)$ & $1.63(1.95)$ & 100 & 100 & 88 & 83 \\
\hline Dachshund & 2.96 & $2.38(2.48)$ & $2.17(2.60)$ & $1.54(2.18)$ & 100 & 96 & 83 & 71 \\
\hline Poodle & 2.93 & 2.67 & 2.75 & $2.13(2.68)$ & 100 & 100 & 100 & 79 \\
\hline Beagle & $2.87(2.94)$ & $2.67(2.78)$ & $1.92(2.71)$ & $1.00(2.18)$ & 98 & 96 & 71 & 46 \\
\hline Greyhound & 2.78 & 2.50 & $2.33(2.44)$ & $1.33(1.88)$ & 100 & 100 & 96 & 71 \\
\hline Mean & $2.93(2.94)$ & $2.65(2.68)$ & $2.32(2.62)$ & $1.69(2.25)$ & 99.71 & 98.86 & 88.71 & 74.43 \\
\hline \multicolumn{9}{|c|}{ Musical Inst ruments $\mathbf{f}$} \\
\hline Flute & 2.98 & 2.63 & $2.17(2.26)$ & $2.00(2.18)$ & 100 & 100 & 96 & 92 \\
\hline Guitar & 2.98 & 2.75 & 2.63 & $2.17(2.26)$ & 100 & 100 & 100 & 96 \\
\hline Piano & 2.98 & 2.92 & 2.58 & $2.50(2.61)$ & 100 & 100 & 100 & 96 \\
\hline Trumpet & 2.98 & 2.75 & $2.46(2.57)$ & 2.42 & 100 & 100 & 96 & 100 \\
\hline Violin & 2.98 & 2.75 & 2.29 & $2.13(2.22)$ & 100 & 100 & 100 & 96 \\
\hline Drum & 2.93 & 2.79 & 2.50 & $2.04(2.13)$ & 100 & 100 & 100 & 96 \\
\hline Accordian & 2.86 & $2.46(2.57)$ & $1.50(2.00)$ & $1.71(2.28)$ & 100 & 96 & 75 & 75 \\
\hline Harmonica & 2.80 & 2.46 & 2.29 & $1.83(2.20)$ & 100 & 100 & 100 & 83 \\
\hline Tamborine & 2.73 & $2.33(2.44)$ & 2.04 & $1.75(2.21)$ & 100 & 96 & 100 & 79 \\
\hline Mean & $2.91(2.91)$ & $2.65(2.67)$ & $2.27(2.35)$ & $2.06(2.28)$ & 100.0 & 99.11 & 96.33 & 90.33 \\
\hline
\end{tabular}

a Typicality ratings ranged from 3 (highly typical) to 1 (atypical). A score of 0 was given to items not included as category exemplars. Adjusted typicality scores, when different from unadjusted scores, are presented in parentheses. bPercentage of subjects at each grade level who included an item as an appropriate category exemplar. Percentage included and typicality ratings were based on a sample of 24 subjects in each of the kindergarten, third, and sixth grades, and 45 subjects in the adult sample. cFoil items used for this category: baby, bell, clown, feather, socks. dFoil items used for this category: bookcase, bridge, bus, fence, letter. eFoil items used for this category: bear, horse, mouse, rabbit, telephone. fFoil items used for this category: brush, key, moon, pan, radio.

(Manuscript received October 12, 1982;

revision accepted for publication April 6, 1983.) 